\title{
Comparison of Fruit Quality Characteristics of Berries
}

\author{
Ebru Yaşa Kafkas \\ Department of Horticulture, Faculty of Agriculture, University of Çukurova, Adana, Turkey \\ Email: ebruyasakafkas@gmail.com
}

How to cite this paper: Kafkas, E.Y. (2021) Comparison of Fruit Quality Characteristics of Berries. Journal of Materials Science and Chemical Engineering, 12, 907-915. https://doi.org/10.4236/as.2021.128058

Received: July 24, 2021

Accepted: August 28, 2021

Published: August 31, 2021

\begin{abstract}
Fruits including berries are one of the most important sources of our daily nutrition due to their major aspect from point of view of consumers. The fruit quality includes the internal and external properties. The internal quality mainly is determined by aroma, flavor, taste, texture, nutritional quality (soluble sugar content, starch, organic acids, soluble solids content, and carotenoids, total flavonoids, total phenolic, antioxidant activity), flesh firmness, diseases, and chemical residues, while the external quality mainly concerns the appearance, size and colour and bruises. How to measure berry fruit quality has always been one of the most attractive research hotspots in the food industry. For the present, most of the available investigative methods are still destructive, labor and time-consuming; besides, several methods require sample preparation, costly instruments and chemicals, which cannot be used for large-scale sample evaluation. With the increasing demands of real-time detection of fruit quality, non-destructive fruit evaluation methods have been greatly developed. However, problems like low detection accuracy and poor model adaptability remain in the non-destructive detection system. Thus, it is necessary to develop non-destructive, high-efficient, simple, accurate and low-labor-cost techniques for fruit quality determination. In this paper, a comparison of different and advanced analytical methods for assessing the fruit quality characteristics of berries was discussed.
\end{abstract}

\section{Keywords}

Berries, Fruit Quality, Chromatography, Analysis Techniques, Flavor

\section{Introduction}

\section{Why Berries?}

Fruits including berries have high importance in world fruit production and for 
human consumption since they are rich in health benefit compounds [1] [2]. Edible berries have been a part of people diet for many centuries. Increasing demand and consumption of healthy and functional foods is one of the most significant current world trends [3]. The term "functional food" originated in Japan in the 80s, and its meaning has varied throughout the World [4]. Health and enjoyment are the two main reasons for eating fruits. Berries are known also as non-wood forest and bioproducts and commonly consumed worldwide and typically used in functional and premium class foodstuffs and nutraceuticals [5]. The recent global interest in the consumption of foods with high levels of functional properties and nutraceuticals compounds is gaining momentum [6]. Among these types of foods, berries are one of the most important functional and nutraceutical foods in our diets [7].

Therefore, they are of great interest to scientists specifically breeders, nutritionists, and food technology experts on berries specifically strawberries (Fragaria $X$ ananassa L.), blackberries (Rubus fructicosus L.), raspberries, blueberries (Vaccinium spp.), white and black mulberries (Morus alba L. and Morus nigra L.), currants (Ribes spp.), raspberries (Rubus ideaus L.) and gojiberries (Lycium barbarum and Lycium chinense) [8]. Berries are rich in high levels of antioxidants, phytochemicals, flavonoids, carotenoids, polyphenols, vitamins, and minerals.

It has been previously reported that a large number of studies have shown a wide range of biological activities and potential health benefits of berries, berry fractions and their products. Compared with other fruit species, berries are unusual in that they are rich in anthocyanins.

Like their pulps, berry seeds also have important benefits since they are rich in oil and comprise essential fatty acids as linoleic (18:2n6) and a-linolenic acid ratios close to one. Furthermore, it has been previously reported that dietary intervention with berry seed oils in the early stage of life may reduce the prevalence of atopic cardiovascular diseases, diabetes, obesity and cancer diseases [9] [10] [11] and [12]. Lifestyle factors, such as diet, obesity, and socioeconomic status, have a profound impact on cancer incidence. Combined, these highlight an increasing demand for strategies for cancer prevention, as there is substantive evidence that diet, nutrition, and physical activity play fundamental roles in cancer and disease prevention [13]. The World Health Organization (WHO) recommends a daily intake of more than $400 \mathrm{~g}$ of fruits and vegetables per person due to their importance in reducing many diseases [2].

Due to their freshly consummated highly colored fruits, delicious taste, low calories and richness of their bioactive compounds, berry fruits have been constantly increasing in popularity over the last few decades. Berry fruits have very low amounts of lipids, but are rich in dietary fibers, and are extraordinary sources of sugars, acids, phenolics, anthocyanins, carotenoids, flavonoids, tannins, vitamins (A, B1, B2, C and PP) and minerals [14].

Berries are fruits which are usually small and rather perishable. For this reason, the consumption of berries in their essence or without losing their quality is 
important. Genetic, environmental and cultural application factors affect the berry fruit quality. Recently breeding and biotechnological approaches are currently used to increase the content of metabolomics in berries. Consumers prefer to buy healthy and pesticide residue-free products. Therefore, more research on the technology fast, reliable, replicable required for determining fruit quality should be needed. Thus, this paper will review the issues on detection of berry fruit quality parameters by advanced technologies that have been applied for measuring them.

\section{Fruit Quality Parameters}

\subsection{Sugars}

Sugars are primary products of photosynthesis, and a fundamental compound correlated with fruit quality and flavor, which determine the caloric value of the fruit. Total soluble solid content of the berries can be detected using fast and very simple methods. The degrees Brix is a simple scientific measure of the total soluble solids (TSS) contained in a liquid. $1{ }^{\circ}$ Brix equals 1 gram of dissolved sucrose sugar in 100 grams of water. The typical degrees Brix measurement can be done with a refractometer, which is available as both classic mechanical versions and modern digital versions. The major disadvantage of the refractometers is that the sample, namely the fruits to be tested, needs to be destroyed to have the fruit juices on the refractometer. With near-infrared spectroscopy the destructive sampling of the fruits can be by passed, and the quality of the fruit can be tested without waste or harmful chemicals. NIR spectroscopy does not require any sample preparation as such, it is easy-practical and fast to use.

HPLC technique can be used to help identify and quantify the sugar content of a wide variety of sample types. The analysis is limited to mono- and disaccharides. Oligosaccharides and polysaccharides may be analyzed for monosaccharide content after enzymatic digestion. Sucrose, glucose and fructose are the main sugars found in fruits of commercial importance [15]. Sorbitol, which is a sugar alcohol, is also present and is important in some fruits [15]. Fructose is 3, 2.3 and 1.7 times sweeter than sorbitol, glucose and sucrose, respectively [16].

\subsection{Acids}

Total acidity is the sum of organic acids and their salts, titratable acid neutralization determined with an alkaline solution (usually $0.1 \mathrm{~N} \mathrm{NaOH}$ ). Determination of total acidity can be done by the following methods: by potentiometric titration method or electro titrimetric: the titration method in the presence of indicators such as phenolphthalein and bromothymol blue, which are inserted into the glass titration instead of phenol red by drops. The result can be expressed conventionally prevailing in the product acid (malic acid, tartaric acid or citric acid). The concentration of organic acids in fruits is important, because they influence the organoleptic properties of fruit juices particularly as regards flavour, colour and aroma. The content of organic acids in fruit juices not only influ- 
ences organoleptic properties but also their stability, nutrition, acceptability and quality. Organic acids in fruits are effective not only in several physiological processes such as taste formation, maturation and are of great importance in human health, also [17] [18]. The ratio of organic acids and sugars reveals the ripening status of the fruit. Organic acids block the effects of heavy metal ions on catalyzing oxidation by constructing complexes with them [18]. Several chromatographic methods have been developed for identifying and quantifying individually organic acids in different matrixes. [19] used liquid chromatography coupled to tandem-mass spectrometry (LC-MS/MS) with triple quadrupole in selective reaction monitoring mode to determine organic acids (glutamic, tartaric, quinic, malonic, malic, shikimic, a-ketoglutaric, pyruvic, citric, succinic and fumaric acids) in fruits including berries, also. [20] identified and quantified organic acid content of several berries by HPLC technique coupled with UV detector.

\subsection{Total Phenolic Compounds}

Berries are rich in the phenolic compounds (phenolic acids, polyphenols and flavonoids) and are gaining increasing attention because of their high antioxidant activity [21]. Phenolic compounds might act as reducing substances, blocking free radicals, chelating metal ions, inhibitors of oxidation reaction, inhibitors of the activity of enzymes contributing to free radical creation. In addition, they may reduce reactive oxygen species to more stable forms [22]. To determine the total phenolic content, the most used method is the method of Folin Ciocalteu by spectrophotometric method. The standard calibration curve was plotted using gallic acid at concentrations of $0.02-0.1 \mathrm{mg} \cdot \mathrm{ml}^{-1}[23]$.

\subsection{Total Anthocyanins}

Anthocyanins are water-soluble plant secondary metabolites consisting of one or more aromatic rings with different degrees of hydroxylation, methoxylation and glycosylation, contributing to fruit colour. Anthocyanins are of great interest to the food industry and can be used as food colourant from natural sources as a promising alternative to synthetic colourants. Berries are commonly red, purple and black colors and among them blackberry, mulberry, blueberry, raspberry fruits are rich in anthocyanin compounds [24] [25].

The total anthocyanin content (TAC) in the berry fruit extracts is usually directly determined using the $\mathrm{pH}$-differential method. The extracts for TAC analysis were prepared using the method described for quantification of total polyphenols. Anthocyanins demonstrate maximum absorbance at $515 \mathrm{~nm}$ at $\mathrm{pH} 1.0$ and also at $700 \mathrm{~nm}$ at $\mathrm{pH} 4.5$.

\subsection{Total Antioxidant Capacity}

Since berries are rich in antioxidants, which are effective for eliminating free radicals and reactive oxygen species that are, in most cases, the cause of chronic 
diseases. That is the reason nutraceuticals and functional foods have become very fashionable for people who want to ensure maximum health benefits from food [26].

The determination of the antioxidant capacity of berries can be performed by different methods such as DPPH radical scavenging activity, Ferric reducing antioxidant power (FRAP), TPTZ (2,4,6-tripyridyl-S-triazine) complex to its ferrous form $\left(\mathrm{Fe}^{2+}\right)$. Hydroxyl radical scavenging activity $(\mathrm{OH} ; \mathrm{HOSC})$, Oxygen radical absorbance capacity (ORAC), free radical capture (ABTS), Nitric oxide-scavenging activity (NO).

\subsection{Color}

The surface or external color of berries has a great influence on the consumer's preference and is an excellent indicator and is the first sensation that the consumer perceives and uses as a tool to either accept or reject food [27].

Colour can be correlated with other quality attributes such as sensory, nutritional and visual or non-visual defects and helps to control them immediately [28] [29]. Food appearance determined mostly by surface colour. Visual appearance of the food manifested as its colour has a strong influence on a consumer's opinion about the food quality [30] [31]. The fruit colour of berries can be measured as lightness $\left(L^{*}\right)$, redness $\left(a^{*}\right)$ and yellowness $\left(b^{*}\right)$ by Minolta Computer vision (CV) is a nondestructive technology used for acquiring and analyzing digital images to obtain information of heterogeneous products. It has been regarded as a valuable simple and fast tool which helps to improve the automatic assessment of food quality. CV has been recently used in the food industry for quality and color evaluation, detection of defects, grading and sorting of berry fruits, among other applications [32].

\subsection{Phenolics}

Phenolic compounds are widely distributed in such plants where they act as attractants for certain insects, as free radical scavengers, and in defence against ultraviolet radiation, pathogens and predators [6] [33]. Recently, chromatographic techniques such as high-performance liquid chromatography (HPLC), HPLC elec-trospray ionization mass spectrometry (HPLC-ESI/MS), gas chromatography-mass spectrometry (GC/MS), capillary electrophoresis (CE), and near-infrared (NIR) spectroscopy techniques are developed for identification, separation, and quantification of phenolics [34].

HPLC-ESI/MS is used to increase the range of phenolic compounds detected in a sample and to improve sensitivity as compared with standard chromatographic methods. HPLC-ESI/MS is a robust and selective quantification method that is effective at measuring the complex array of phenolics typically found in fruits and vegetables. Mass spectrometry methods can be performed on a variety of instruments including electrospray ionization ion trap instruments (HPLCESI-ITMS) triple quadrupole instruments (HPLC-ESI-QQQ-MS/MS), and 
time-of flight instruments (HPLC-ESI-TOF/MS) [35].

\subsection{Aroma}

Identification of key volatile flavor metabolites provides the principal sensory identity and characteristic flavor of the fruit. Volatile compounds such as esters, ketones, aldehydes, terpenes, alcohols, furanones, and sulfur compounds are important quality attribute of strawberry. The volatile components of strawberry fruits vary according to genotypes or cultivars and growth and agronomic conditions [36].

With the fast development of science and technology especially the application of GC-MS and other analytical apparatus, progress in aroma research has been made in several fields [37]. Several analytical methods have been developed for the extraction and determination of strawberry aroma compounds. Solid Phase Micro Extraction (SPME) consists of a fused-silica fibre coated with a polymeric stationary phase which is introduced into a liquid or gas sample. The method involves two processes: the partitioning of the analytes between the coating and the sample and the thermal desorption of the analytes into the gas chromatograph [38]. Another extraction method known as liquid-liquid extraction (LLE) is certainly one of the most frequently reported methods in the literature for the isolation of volatile compounds in fruits. Nevertheless, because LLE requires large amounts of high-purity solvents, this technique is relatively tedious and time-consuming. Furthermore, extracts often have to be concentrated hundreds of times, and loss of analytes and artifact formation, due to elevated temperatures, during the concentration step are generally observed [39]. In this experiment, two different extraction methods HS-SPME (Headspacesolid phase micro extraction) and liquid-liquid extraction were used to identify Turkish domestic strawberry genotypes using various extraction techniques by GC/MS [40].

\section{Conclusion}

As a conclusion, analysis methods of fruit quality parameters are important and the results can be changed based on the utilized techniques that were applied. Fruit quality of berry fruits varies depending on the genotypes or cultivars and cultivation techniques, applications and agronomic conditions. Since their health benefits properties berries should take a place in daily meal in people as a functional food.

\section{Conflicts of Interest}

The author declares no conflicts of interest regarding the publication of this paper.

\section{References}

[1] Dris, D. and Jain, S.M. (2004) Production Practices and Quality Assessment of Food 
Crops. Volume 1: Preharvest Practice. Kluwer Academic Publishers, Dordrecht, The Netherlands, 261-285. https://doi.org/10.1007/1-4020-2533-5

[2] Joffe, M. and Robertson, A. (2001) The Potential Contribution of Increased Vegetable and Fruit Consumption to Health Gain in the European Union. Public Health Nutrition, 4, 893-901. https://doi.org/10.1079/PHN2001126

[3] Granato, D., Branco, G.F., Cruz, A.G., Faria, J. de A.F. and Shah, N.P. (2010) Probiotic Dairy Products as Functional Foods. Compr Rev Food Sci Food Saf, 9, 455-470. https://doi.org/10.1111/j.1541-4337.2010.00120.x

[4] Lau, T.C., Chan, M.W., Tan, H.P. and Kwek, C.L. (2013) Functional Food: A Growing Trend among the Health Conscious. Asian Soc Sci, 9, 198-208. https://doi.org/10.5539/ass.v9n1p198

[5] Peltola, R. and Manninen, O.H. (2013) Effects of Picking Methods on the Berry Production of Bilberry (Vaccinium myrtillus), Lingonberry (V. vitis-idaea) and Crowberry (Empetrum nigrum ssp. hermaphroditum) in Northern Finland. https://doi.org/10.14214/sf.972

[6] Zimmer, K.R., Blum-Silva, C.H., Souza, A.L.K., WulffSchuch, M., Reginatto, F.H., Pereira, C.M.P. and Lencina, C.L. (2014) The Antibiofilm Effect of Blueberry Fruit Cultivars against Staphylococcus epidermidis and Pseudomonas aeruginosa. Journal of Medicinal Food, 17, 324-331. https://doi.org/10.1089/jmf.2013.0037

[7] Kähkönen, M.P., Hopia, A.I. and Heinonen, M. (2001) Berry Phenolics and Their Antioxidant Activity. Journal of Agricultural and Food Chemistry, 49, 4076-4082. https://doi.org/10.1021/jf010152t

[8] Gündeşli, M.A., Korkmaz, N. and Okatan, N. (2019) Polyphenol Content and Antioxidant Capacity of Berries: A Review. International Journal of Agriculture, Forestry and Life Sciences, 3, 350-361.

[9] Yang, B. and Kortesniemi, M. (2015) Clinical Evidence on Potential Health Benefits of Berries. Current Opinion in Food Science, 2, 36-42. https://doi.org/10.1016/j.cofs.2015.01.002

[10] Johansson, A., Laakso, P. and Kallio, H. (1997) Characterization of Seed Oils of Wild, Edible Finnish Berries. Zeitschrift Fur Lebensmittel-Untersuchung Und-Forschung A-Food Research and Technology, 204, 300-307. https://doi.org/10.1007/s002170050081

[11] Johansson, A., Laine, T., Linna, M.M. and Kallio, H. (2000) Variability in Oil Content and Fatty Acid Composition in Wild Northern Currants. European Food Research and Technology, 211, 277-283. https://doi.org/10.1007/s002170000151

[12] Yang, B., Ahotupa, M., Maata, P. and Kallio, H. (2011) Composition and Antioxidative Activities of Supercritical $\mathrm{CO}_{2}$-Extracted Oils from Seeds and Soft Parts of Northern Berries. Food Research International, 44, 2009-2017. https://doi.org/10.1016/j.foodres.2011.02.025

[13] World Cancer Research Fund/American Institute for Cancer Research. (2018) Diet, Nutrition, Physical Activity and Cancer: A Global Perspective. Continuous Update Project Expert Report. A Summary of the Third Expert Report 2018. https://www.wcrf.org/dietandcancer/resources-and-toolkit

[14] Milivojević, J., Rakonjac, V., Akšić, M.F., Bogdanović Pristov, J. and Maksimović, V. (2013) Classification and Fingerprinting of Different Berries Based on Biochemical Profiling and Antioxidant Capacity. Pesqui. Agropecu. Bras., 48, 1285-1294. https://doi.org/10.1590/S0100-204X2013000900013

[15] Wrolstad, R.E. and Shallenberger, R.S. (1981) Free Sugars and Sorbitol in Fruits a 
Compilation from the Literature. Journal of the Association of Official Analytical Chemists, 64, 91-103. https://doi.org/10.1093/jaoac/64.1.91

[16] Kulp, K., Olewnik, M., Lorenz, K. and Collins, F. (1991) Starch Functionality in Cookie Systems. Starch-Stärke, 43, 53-57. https://doi.org/10.1002/star.19910430205

[17] Cemeroğlu, B. and Acar, J. (1986) Meyve ve sebze işleme teknolojisi. Gıda Tek Der, 6, 29-30. (In Turkish)

[18] Savran, H.S. (1999) Nar suyunda organik ait dağılımı (Yüksek Lisans Tezi) AÜ. Fen Bilimleri Enstitüsü, Ankara.

[19] Flores, P., Hellín, P. and Fenoll, J. (2012) Determination of Organic Acids in Fruits and Vegetables by Liquid Chromatography with Tandem-Mass Spectrometry. Food Chemistry, 132, 1049-1054. https://doi.org/10.1016/j.foodchem.2011.10.064

[20] Kafkas, N.E., Oğuz, I. and Oğuz, H.I. (2021) Evaluation of Fruit Characteristics of Various Organically-Grown Goji Berry (Lycium barbarum L., Lycium chinense Miller) Species during Ripening Stages. Journal of Food Composition and Analysis, 101, Article ID: 103846. https://doi.org/10.1016/j.jfca.2021.103846

[21] Chryssavgi, G., Vassiliki, P., Athanasios, M., Kibouris, T. and Michael, K. (2008) Essential Oil Composition of Pistacia Lentiscus L. and Myrtus Communis L.: Evaluation of Antioxidant Capacity of Methanolic Extracts. Food Chemistry, 107, 11201130. https://doi.org/10.1016/j.foodchem.2007.09.036

[22] Kobus-Cisowska, J., Gramza-Michalowska, A., Kmiecik, D., Flaczyk, E. and Korczak, J. (2013) Mulberry Fruit as an Antioxidant Component in Muesli. Agricultural Sciences, 4, 130-135. https://doi.org/10.4236/as.2013.45B024

[23] Donno, D., Cerutti, A.K., Prgomet, I., Mellano, M.G. and Beccaro, G.L. (2015) Foodomics for Mulberry FRUIT (Morus spp.): Analytical Fingerprint as Antioxidants' and Health Properties' Determination Tool. Food Research International, 69, 179188. https://doi.org/10.1016/j.foodres.2014.12.020

[24] Kaume, L., Howard, L.R. and Devareddy, L. (2012) The Blackberry Fruit: A Review on Its Composition and Chemistry, Metabolism and Bioavailability, and Health Benefits. J Agric Food Chem, 60, 5716-5727. https://doi.org/10.1021/jf203318p

[25] Paredes-López, O., Cervantes-Ceja, M.L., Vigna-Pérez, M. and Hernández-Pérez, T. (2010) Berries: Improving Human Health and Healthy Aging, and Promoting Quality Life a Review. Plant Foods for Human Nutrition, 65, 299-308. https://doi.org/10.1007/s11130-010-0177-1

[26] Skrovankova, S., Sumczynski, D., Mlcek, J., Jurikova, T. and Sochor, J. (2015) Bioactive Compounds and Antioxidant Activity in Different Types of Berries. International Journal of Molecular Sciences, 16, 24673-24706. https://doi.org/10.3390/ijms161024673

[27] Leon, K., Mery, D., Pedreschi, F. and Leon, J. (2006) Color Measurement in L* a* b* Units from RGB Digital Images. Food Research International, 39, 1084-1091. https://doi.org/10.1016/j.foodres.2006.03.006

[28] Francis, F.J. (1995) Quality as Influenced by Color. Food Quality and Preference, 6, 149-155. https://doi.org/10.1016/0950-3293(94)00026-R

[29] Kramer, A. (1976) Use of Color Measurement in Quality Control of Foods. Food Technology.

[30] Nisha, P., Singhal, R.S. and Pandit, A.B. (2011) Kinetic Modelling of Colour Degradation in Tomato Puree (Lycopersicon esculentum L.). Food and Bioprocess Technology, 4, 781-787. https://doi.org/10.1007/s11947-009-0300-1

[31] Pereira, R.B., Harker, F.R., Carr, B.T., Lenjo, M., MacRae, E.A., Wismer, W.V. and 
Marsh, K.B. (2009) Consumer Liking for Kiwifruit Flavour: A Meta-Analysis of Five Studies on Fruit Quality. Food Quality and Preference, 20, 30-41. https://doi.org/10.1016/j.foodqual.2008.07.001

[32] Matiacevich, S., Silva, P., Enrione, J. and Osorio, F. (2011) Quality Assessment of Blueberries by Computer Vision. Procedia Food Science, 1, 421-425. https://doi.org/10.1016/j.profoo.2011.09.065

[33] Solovchenko, A. and Schmitz Eiberger, M. (2003) Significance of Skin Flavonoids for UVB Protection in Apple Fruits. Journal of Experimental Botany, 54, 1977-1984. https://doi.org/10.1093/jxb/erg199

[34] Xu, C., Wang, B., Pu, Y.Q., Tao, J.S. and Zhang, T. (2017) Advances in Extraction and Analysis of Phenolic Compounds from Plant Materials. Chinese Journal of Natural Medicines, 15, 721-731. https://doi.org/10.1016/S1875-5364(17)30103-6

[35] Maldini, M., Montoro, P. and Pizza, C. (2011) Phenolic Compounds from Byrsonima crassifolia L. Bark: Phytochemical Investigation and Quantitative Analysis by LC-ESI MS/MS. Journal of Pharmaceutical and Biomedical Analysis, 56, 1-6. https://doi.org/10.1016/j.jpba.2011.03.032

[36] Zhang, Y.T., Wang, G.X., Jing, D., Zhong, C.F., Jin, K., Li, T.Z. and Han, Z.H. (2009) Analysis of Volatile Components in Strawberry Cultivars Xingdu 1 and Xingdu 2 and Their Parents. Agricultural Sciences in China, 8, 441-446. https://doi.org/10.1016/S1671-2927(08)60230-8

[37] Song, J. and Forney, C.F. (2008) Flavour Volatile Production and Regulation in Fruit. Canadian Journal of Plant Science, 88, 537-550. https://doi.org/10.4141/CJPS07170

[38] Arthur, C.L. and Pawliszyn, J. (1990) Solid Phase Microextraction with Thermal Desorption Using Fused Silica Optical Fibers. Analytical Chemistry, 62, 2145-2148. https://doi.org/10.1021/ac00218a019

[39] Aubert, C., Baumann, S. and Arguel, H. (2005) Optimization of the Analysis of Flavor Volatile Compounds by Liquid-Liquid Microextraction (LLME). Application to the Aroma Analysis of Melons, Peaches, Grapes, Strawberries, and Tomatoes. Journal of Agricultural and Food Chemistry, 53, 8881-8895. https://doi.org/10.1021/jf0510541

[40] Nogay, G., Ürün, I., Attar, Ş.H., Kafkas, S. and Kafkas, N.E. (2021) Identification of Volatile Compounds of Turkish Local Strawberry Genotypes Using Various Extraction Techniques by GC/MS. 9 th International Strawberry Symposium, 1309, 873-878. https://doi.org/10.17660/ActaHortic.2021.1309.125 